This article was published in Bioresource Technology, 168, 151-158, 2014 http://dx.doi.org/10.1016/j.biortech.2014.04.091

\title{
Sustainability and economic evaluation of microalgae grown in brewery wastewater
}

Teresa M. Mata ${ }^{\text {a, }}$, Adélio M. Mendes ${ }^{a}$, Nídia S. Caetano ${ }^{a, b}$, António A. Martins ${ }^{\mathrm{c}}$

a Laboratory for Process Engineering, Environment, Biotechnology and Energy (LEPABE), Faculty of Engineering, University of Porto (FEUP), R. Dr. Roberto Frias S/N, 4200-465 Porto, Portugal

b Department of Chemical Engineering, School of Engineering (ISEP), Polytechnic Institute of Porto (IPP), R. Dr. António Bernardino de Almeida S/N, 4200-072 Porto, Portugal

c Department of Environmental Engineering, Faculty of Natural Sciences, Engineering and Technology (FCNET), Oporto Lusophone University, R. Dr. Augusto Rosa, 24, 4000-098 Porto, Portugal

\begin{abstract}
This article evaluates the sustainability and economic potential of microalgae grown in brewery wastewater for biodiesel and biomass production. Three sustainability and two economic indicators were considered in the evaluation within a life cycle perspective. For the production system the most efficient process units were selected. Results show that harvesting and oil separation are the main process bottle- necks. Microalgae with higher lipid content and productivity are desirable for biodiesel production, although comparable to other biofuel's feedstock concerning sustainability. However, improvements are still needed to reach the performance level of fossil diesel. Profitability reaches a limit for larger cultivation areas, being higher when extracted biomass is sold together with microalgae oil, in which case the influence of lipid content and areal productivity is smaller. The values of oil and/or biomass prices calculated to ensure that the process is economically sound are still very high compared with other fuel options, especially biodiesel.
\end{abstract}

\section{Introduction}

The need to reduce the environmental impacts and concerns associated with energy supply and its security, mainly due to the current dependence on fossil fuels, has generated an intense search for new energy sources, in particular renewable and with minor environmental impacts (Mata et al., 2011). Among the various possibilities, biodiesel is seen as a viable option in the medium to long term, 
especially in the transportation sector, where other renewable energy sources, such as wind and hydroelectric, currently do not have a significant expression. However important issues still need to be resolved so that biodiesel can reach a greater importance as an alternative to fossil fuels. For example, due to seasonal and agricultural restrictions it has limited supply of raw materials, which include for example edible vegetable oils (Morais et al., 2010), animal waste fats (Mata et al., 2010a), or even other fatty residues such as spent coffee grounds (Caetano et al., 2012). On the other hand, the same raw materials can be used as food for human consumption, which lead to negative economic, social and environmental impacts (Mata et al., 2013a).

Currently, there is a growing consensus that microalgae are one of the best options to replace the dominant feedstock, not only for biofuels but also to obtain bioproducts of high added-value (Mata et al., 2010b). They can grow and be harvested almost continuously, without the limitation of seasonality of most current materials, mainly from agricultural sources. Depending on the species or strain, high biomass and lipid productivities are normally obtained with low cultivation requirements. For example, a wide variety of cultivation media can be used, including fresh, brackish and salt water and various nutrient sources are possible, among which, waste streams such as wastewaters (Mata et al., 2013b) and $\mathrm{CO}_{2}$ flue gas emissions (Maeda et al., 1995). In particular, the coupling between waste treatment and microalgae cultivation may reduce the overall environmental impact and costs (e.g. associated with microalgae growth, waste treatment and disposal), and represent an additional revenue source through the utilization by the company of biofuel produced on site, lipids sold, or exchanged for carbon credits (Mata et al., 2012).

Yet, their commercial and industrial scale development is still on its infancy and significant challenges still need to be tackled to ensure that microalgae are commercially competitive when compared to other energy sources. For example, their cultivation and biomass processing need to be improved and optimized, in particular due to the large volumes of culture medium and biomass to be processed, and the separation and concentration of algal bio- mass should ensure that lipid extraction is efficient from both energy and material point of views (Mata et al., 2010b).

The current state of affairs also represents an opportunity to ensure that the development and commercial implementation of microalgae biofuels are done properly, taking into account not only the economic aspects, but also the other dimensions of sustainability, namely societal and the environmental. Thus, a comprehensive, objective, and consistent sustainability assessment of the existing and/or future options for microalgae cultivation and processing, either for biofuels production or for other chemicals, is vital. The results of a sustainability assessment may serve many purposes. For example, based on the 
results it will be possible to select the most adequate process layout and units for new biofuel plants, or to identify bottlenecks and/or constraints to improve the overall sustainability of existing facilities. From a strategic point of view sustainability assessment is relevant to ensure that the right decisions are made, and that the most adequate certification schemes, policies, and incentives are developed and implemented.

Hence, this study evaluates the sustainability and economic viability of microalgae grown in brewery wastewater, as an alternative feedstock for biodiesel and biomass production.

\section{Methods}

\subsection{Process description: assumptions and conditions}

For the sustainability and economic evaluations of microalgae biodiesel, the whole life cycle was taken into account (Mata et al., 2013a), considering the most effective methods and technical options for the biomass processing. Thus, the life cycle steps comprise: microalgae cultivation, harvesting, biomass processing for lipids extraction (including the dewatering, high pressure homogenization and three phase centrifugation), microalgae oil transportation, biodiesel production and its final use.

For the sustainability evaluation all the life cycle steps were considered, but for the economic analysis only the steps inside the brewery domain were accounted for, including: microalgae cultivation, biomass harvesting, and biomass processing for lipids extraction (as shown in Fig. 1).

The functional unit of $1 \mathrm{MJ}$ of energy output was considered, allowing comparison of the sustainability of microalgae biodiesel with other biofuels and fossil diesel.

Among the various potential microalgae species currently being studied for biodiesel production, in this case study it was chosen the freshwater microalgae Scenedesmus obliquus (S. obliquus). This is because it has shown experimentally to be very versatile (Ruiz-Marin et al., 2010), being able to adapt with success to wastewaters of various origins, such as from brewery (Mata et al., 2012, 2013b), olive oil plant (Hodaifa et al., 2010) and municipal (Mandal and Mallick, 2011). Key aspects of this microalga include small nutrient requirements, high lipid content suitable for biodiesel, commonly between 11\% and 55\% (Mata et al., 2010b), optimal growth temperature between 25 and $30{ }^{\circ} \mathrm{C}$ (Hodaifa et al., 2010), although it can tolerate a wider temperature range, making it adequate for outdoor cultivation in most climates, and the possibility of maximizing biomass productivity by per-forming cultivation and harvesting in a continuous mode. Based on experimental data for S. obliquus grown in brewery wastewater (Mata et al., 2013b), the following parameters can be assumed as realistic for 
the system under study: a microalgae lipid content of about $30 \% \mathrm{dwt}$, a biomass concentration of $0.9 \mathrm{~kg} / \mathrm{m}^{3}$, and areal productivity of $30 \mathrm{~g} / \mathrm{m}^{2} / \mathrm{d}$ for a biomass residence time of about 9 days. Although in this study some of the previous parameters will be varied, they will serve as a basis for the calculations.

For microalgae cultivation it is considered open ponds as they are easier and cheaper to operate than other large scale cultivation systems, in particular photobioreactors, even though less efficient from a biomass productivity perspective (Mata et al., 2010b).

Some cultivation assumptions were made based on data obtained experimentally for S. obliquus grown in brewery waste- water (Mata et al., 2013b). These include: a microalgae lipid con- tent of about $30 \% \mathrm{dwt}$, a biomass concentration of $0.9 \mathrm{~kg} / \mathrm{m}^{3}$, and an areal productivity of $30 \mathrm{~g} / \mathrm{m}^{2} / \mathrm{d}$ for a biomass residence time of about 9 days.

Of the several technologies available for microalgae harvesting (e.g. disk stack, bowl, tubular bowl and scroll discharger) in this study it is considered a disk stack centrifuge (Molina Grima et al., 2003). This step is critical to the economic and sustainability viability of microalgae cultivation, as large energy inputs are required (Mata et al., 2010b). The best method to harvest microalgae heavily depends on their characteristics and which product(s) are desired. Key aspects that have to be taken into account are the dilute nature of microalgae suspensions (frequently more than 99\% water and cell densities as low as 0.5 $\mathrm{g} / \mathrm{L}$ ), the small cell size in the range of micrometers, and the potential presence of contaminants. Filtration and sedimentation are other methods that can be used in this step. In particular, sedimentation can be enhanced by centrifugation, which is becoming the preferred harvesting method of microalgae (Benemann and Oswald, 1996), since it is more efficient to recover small size cells with low mass concentrations. Also, it is very flexible in terms of production capacities, is robust, has high recovery rates normally in excess of $90 \%$, and can significantly reduce the water content.

For the mechanical cell disruption, this study considers a high pressure homogenizer (Smith and Charter, 2010), where disruption of cell walls is achieved by change of pressure between the entrance and expansion exit of this device. This method has the advantages of no chemicals needed and preservation of cell components. Cell disruption is necessary to free the intracellular components of microalgae and facilitate separation of the desired components, in particular lipids. Traditional extraction methods, in particular solvent based, are not efficient in this context, due to the presence of large quantities of water and many different types of components, leading to selectivity issues and eventual problems in biodiesel production.

For lipids extraction and separation a three-phase continuous centrifuge is 
considered, following the suggestion of Benemann and Oswald (1996) of mixing the biomass at the entrance with a fraction of the lipids obtained in the centrifuge to increase the overall separation efficiency, up to $98 \%$.

For biodiesel production it is considered the transesterification of triglycerides in stoichiometric excess of methanol, homogenously catalyzed by a strong alkalicatalyst (usually $\mathrm{NaOH}$ ) (Khoo et al., 2011). High purity feedstocks are required for this process, as contaminants (e.g. water, free fatty acids) lead to low reaction yields and production of undesirable byproducts. Other possibilities are being proposed in literature, but they are not in a state of development allowing their industrial implementation. Thus, in this work the referred process was selected as it is simple to implement and control, has mild processing conditions, and has available more experimental and technical data (Khoo et al., 2011).

Due to operational limitations and equipment limit capacity, it is assumed that harvesting and biomass processing is done on a semi continuous' operation mode, of $8 \mathrm{~h}$ cycles, only microalgae cultivation is operated continuously.

The cultivation and biomass processing occurs at the brewery site and the oil extracted is transported to a dedicated external biofuel's plant at about $50 \mathrm{~km}$ distance from the brewery.

For the sustainability evaluation, the data concerning energy needs to power the process units (Molina Grima et al., 2003; Khoo et al., 2011), fossil fuel needs for the microalgae oil transportation (Mata et al., 2011; SunEarthTools, 2013), and respective GHG emissions, were obtained from literature and technical descriptions, assuming that energy consumption in the process is directly proportional to the quantity of microalgae biomass processed.

The net GHG emissions from the process were calculated based on the energy consumption data, summing the GHG emitted in each process unit and subtracting the carbon capture during microalgae growth. This considers the energy mix typical of Portugal and that, to generate the electrical energy for the process units, $0.094 \mathrm{~kg}$ of $\mathrm{CO} 2$-equivalent is emitted per MJ of electricity.

For estimating the carbon capture during microalgae growth it is considered that algal biomass has a molecular composition of $\mathrm{C} 106 \mathrm{H} 263 \mathrm{O} 110 \mathrm{~N} 16 \mathrm{P}$ (Shurin et al., 2013). Thus, as a consequence of microalgae photosynthesis, nitrate and phosphate are taken up together with carbon in the mass proportion of C/N/P of about 106:16:1.

Regarding the economic analysis, several items were taken into account. Two main products are generated in the process: microalgae oil, sold to a biodiesel facility, and residual biomass that can be sold for other purposes. Both represent the process sole sources of revenue. The potential utilization of biomass to serve as an energy source in the process is not considered.

The capital investment for the acquisition and construction of process units and other fixed assets is considered, assuming a project life span of 10 years for the 
investment amortization. For the calculations it is considered a WACC (weighted average cost of capital) of $7.5 \%$ assuming $100 \%$ of total capital debt, with a debt cost of $10 \%$ and a corporate tax rate of $25 \%$ (KPMG, 2013).

It is assumed that the land necessary to build the raceways ponds is available at no cost at the brewery site. Thus, only the capital for the raceways construction and operation was accounted for. Regarding costs, the main items are the acquisition and construction costs of the process units, and the operational (labor and maintenance) costs. It is assumed that the $\mathrm{CO} 2$ and nutrients needed to grow microalgae are obtained at no cost from the waste streams generated in the brewery process, in particular wastewater.

\subsection{Sustainability and economic evaluation: methodology and indicators}

Following the methodology described in literature (Mata et al., 2011, 2013a) and the main assumptions listed above, three sustainability indicators were selected for this study: the life cycle energy efficiency (LCEE), fossil energy ratio (FER) and contribution to global warming (GW) calculated as Eqs. (1)-(3), respectively.

LCEE is the ratio of the total energy output, consisting of the energy content of the biofuel, plus that of byproducts only if they are used to supply energy to the biofuel production system, to the amount of energy expended to obtain the biofuel (dimensionless).

$$
\text { Life cycle energy efficiency }(\text { LCEE })=\frac{\text { Total energy output }}{\text { Total energy input }}
$$

FER is the ratio between the energy content of the final fuel product (or the fuel energy output) and the amount of fossil energy input (or the non-renewable energy) required for the fuel production through the supply chain

$$
\text { Fossil energy ratio(FER) }=\frac{\text { Fuel energy output }}{\text { Fossil energy input }}
$$

Concerning the calculation of LCEE and FER, the energy consumption of each process unit, associated with each life cycle step, was considered in the "total energy input" and "fossil energy input" denominators of the LCEE and FER equations, respectively, based on energy data and technical information available from suppliers or open literature. In particular, the amount of "fossil energy input" was estimated based on the energy mix of the region where the brewery of this case study is located, and considering other sources of data, in particular for the transportation steps.

GW measures the potential contribution of different GHG (greenhouse gas) emissions to global warming, expressed as equivalent $\mathrm{CO} 2$ emission per unit 
energy of fuel product (kg CO2-eq/MJ fuel).

Contribution to global warming $(\mathrm{GW})=\sum_{i} G W P_{i} \times E_{i}$

where $E_{i}$ is the mass of compound $i$ emitted to the air and GWPi is the global warming potential of the compound $i$, calculated as the net GHG emissions through the fuel life cycle.

Additionally, two economic indicators were considered for the economic analysis: the internal rate of return (IRR) and the net present value (NPV). These two economic indicators are calculated based on the cash flows generated by a project during its useful life. Both take into account the temporal value of money through an interest rate, depending on the overall economic conditions.

NPV is calculated in terms of monetary value, while IRR is expressed in terms of the interest rate a firm expects for the project investment. Thus, both indicators give complimentary information about the investment in a project and should be considered simultaneously. Academic evidence suggests that the NPV indicator is preferred, since it calculates the added value generated by the project, an aspect that the IRR does not consider. However, the IRR has the advantage that managers tend to better understand the concept of returns stated in interest rates and percentages, and find it easier to compare to the cost of capital.

Although with both the NPV and the IRR one may reach similar conclusions about a project, the use of IRR can lead to the belief that a smaller project with a shorter life and larger cash flows at the initial stages is preferable to a larger project that will generate more cash but distributed in a longer period of time. Also, using different WACC to calculate the NPV will result in different recommendations, while the IRR method always gives the same recommendation.

\section{Results and discussion}

\subsection{Calculation parameters}

Many parameters can influence the sustainability and economic performance of growing microalgae for biodiesel and biomass, in particular: cultivation area, lipid content and productivity, biomass productivity, efficiency of the process units and selling prices of the microalgae oil and extracted biomass (Campbell et al., 2011; Pfromm et al., 2011; Delrue et al., 2012).

Concerning the efficiency of the process units, a literature search was conducted in this study in order to select the most efficient process units and methods for the 
microalgae cultivation and biomass processing plant (shown in Fig. 1).

Land use may be one relevant parameter when there are space constraints, which is not the case in this study. It is expected that its effects on the process sustainability and economic viability are smaller than the lipid content and productivity that have a much stronger influence. These last two parameters are interconnected, and depend on the characteristics of the microalgae cultivation systems. Therefore, this study will focus attention on the following main factors: microalgae lipid content, areal productivity, and selling prices of lipids and extracted biomass.

\subsection{Sustainability evaluation}

Calculations showed that sustainability indicators (LCEE, FER and GW) do not depend on the cultivation area but are strongly influenced by microalgae lipid content. This is because these indicators are measured in relation to the functional unit, of $1 \mathrm{MJ}$ of energy generated, which depends on the total biomass produced and processed, assumed to be proportional to the cultivation area and energy consumption. Thus, for LCEE and FER the increase in energy consumption, due to an increase in biomass processing, is exactly compensated by the increase in the energy obtained in the system, making both indicators independent of the cultivation area. A similar situation occurs for $\mathrm{GW}$ that is proportional to the energy consumed in the system.

An interesting feature of the methodology used in this work for the sustainability evaluation is the possibility of identifying which life cycle stages are the most relevant ones, and where improvements can have bigger impact. As an illustration, the graph of Fig. 2a shows the relative percentage of each life cycle step contributing to energy consumption as a function of microalgae lipid con- tent (15, 20 and $30 \mathrm{wt} \%$ ). These relative percentages are determined by dividing the energy needed in each life cycle step by the overall life cycle energy needs.

Fig. 2a shows the largest energy needs for biomass processing, especially for harvesting and first dewatering (using the disk stack centrifuge) and for the lipids separation from biomass and water (using the 3-phase centrifugation). This result agrees with the literature (Molina Grima et al., 2003) that states that energy efficient water removal and lipids separation processes are critical issues for the competitiveness of microalgae as feedstock for biodiesel production, and to reduce the overall life cycle environmental impact (Lardon et al., 2009). Increasing the lipid content slightly reduces the relative contribution of energy consumption (measured as a relative percentage) in the biomass processing steps, while it increases in the biodiesel production and distribution steps. How- ever, the dominant steps in terms of energy consumption are still the same, regardless of the microalgae lipid content, leading support to the conclusion that one should focus on improving the biomass 
processing steps, by for example, increasing the energy efficiency of the process equipment, or by using better technologies, or new production methods for biodiesel production requiring less biomass processing, among others. This is currently a very active field of research, and new developments are expected soon in this area.

Fig. 2b presents the relative percentage of each life cycle step contributing to the net GHG emissions as a function of microalgae lipid content (15, 20 and 30 wt\%). These relative percentages were determined by dividing the GHG emissions of each life cycle step by the overall life cycle GHG emissions.

Fig. 2b shows that, when considering the overall life cycle, fuel use is the most relevant step in terms of GHG emissions. Biomass processing is also relevant to a lesser extent as expected, since the biomass processing steps with higher relative energy consumption (Fig. 2a) are also the ones with larger relative contribution to GHG emissions.

The savings from carbon capture due to microalgae growth is also relevant but this value is indicated as negative since it needs to be subtracted from the overall life cycle GHG emissions in order to determine the net GHG emissions and thus, the contribution to global warming. As expected, at higher lipid content the relative saving from carbon capture is smaller as the relative contribution to GHG of fuel use is larger. This is expected because smaller quantities of algal biomass need to be cultivated and processed to obtain the same amount of energy ( $1 \mathrm{MJ}$ of biodiesel, the functional unit for this study) and the GHG emissions directly depends on the energy consumption in each process step. Also, at higher lipid content the relative contribution to GHG emissions is lower in the biomass processing steps (cultivation, harvesting and lipids extraction) and higher in the lipids transportation, biodiesel production and fuel use steps. The same way, the decrease in the relative contribution of GHG during biomass processing, at higher lipid content, is due to the smaller relative energy consumption (and thus smaller emissions) to obtain the same quantity of biofuel.

Table 1 presents the values of the three sustainability indicators, LCEE, FER and GW, calculated for the system considered with microalgae lipid contents of 15, 20 and $30 \mathrm{wt} \%$ (as in Fig. 2a and b).

The table also presents the results of another study (Mata et al., 2011), for comparison purposes, where the sustainability of biodiesel based on various feedstocks and also fossil diesel was assessed. The results show that, in terms of the sustainability indicators analyzed, biodiesel from microalgae $S$. obliquus grown in brewery wastewater and processed as described above is comparable to biodiesel obtained from other feedstocks and, in particular, to bio- diesel from other microalgae species (Table 1). Concerning the LCEE and FER, fossil diesel is always superior, but the GW of fossil diesel is not as good as of biodiesel from palm, sunflower and rapeseed, which are currently the most common biodiesel feedstocks. Although it seems that fossil fuel is better from a sustainability point of view 
when compared to biodiesel, regardless the feedstock considered, it has a nonrenewable nature, and thus it is unsustainable in a fundamental way. Yet, its inclusion in the comparison between biofuels is justified as fossil diesel is among the dominant fuels currently used in the transportation sec- tor (the other being gasoline). And since biodiesel can be used mainly in diesel engines, diesel represents a reasonable comparison benchmark.

As shown in Table 1, for a lipid content of $30 \mathrm{wt} \%$, microalgae biodiesel is better is terms of LCEE and FER than soybean biodiesel (with a lipid content of $18 \mathrm{wt} \%$ ), but not significantly different to biodiesel from the other feedstocks. With a lipid content of 15-20 wt\%, microalgae biodiesel is not energy efficient (since LCEE is lower than unit). Therefore it is not worth producing it using the production system considered in this work. One may conclude that the sustainability viability of biodiesel from microalgae is much dependent on their lipid content, which is a key factor also for the process economic sustainability.

Results of this case study showed that microalgae lipid content has a significant influence on the sustainability of biodiesel produced from it, in particular the larger the better. Also it seems that for a lipid content greater than $30 \mathrm{wt} \%$ the microalgae biodiesel will be better than the other biodiesel feedstock options. To verify this statement more values of lipid content have been considered, keeping the remaining factors constant. Therefore, graphs of Fig. 3 present the sustainability indicators LCEE, FER and GW at lipid con- tents varying from 3 to $65 \mathrm{wt} \%$.

FER and LCEE show an almost linear dependence on the lipid content value. Concerning LCEE, for high values of lipid content it is better than biodiesel from other feedstocks. Although FER increases significantly, it never surpasses fossil fuel.

Since the lipid content is a key factor for increasing the sustain- ability of microalgae biodiesel, improvements in the life cycle are still necessary to ensure that it is really the more adequate option. In particular, the first dewatering and lipids separation steps of biomass processing should be considered with special attention, as they are the main energy consumers, as shown in Fig. 2.

Concerning GW, Fig. 3 shows that this indicator values are always positive for the system under study. Hence, the carbon captured in microalgae growth does not compensate the carbon emit- ted in the process, mainly due to its energy needs, thus making the biodiesel not carbon neutral neither carbon negative. A possible solution to this issue is the utilization of renewable and/or carbon free energy sources in the biodiesel production process.

On the other hand, although the full range of values considered for the microalgae lipid content, GW reaches a minimum limit value of around $0.10 \mathrm{~kg} \mathrm{CO} 2-\mathrm{eq} / \mathrm{MJ}$ biodiesel. The abrupt reduction in the GW for lower values of lipid content (between 3 and around $20 \mathrm{wt} \%$ ) occurs because the energy needs at biomass processing per unit of biodiesel produced (1 MJ) leads to much higher GHG emissions, which is not 
compensated by the carbon capture that is much lower (Fig. 2a and b). For lipid contents higher than about $30 \mathrm{wt} \%$ the reduction in the carbon capture during microalgae growth is compensated by the lower GHG emissions during bio- mass processing, as the energy requirements are smaller per unit of biodiesel produced (Fig. 2a and b). Thus, for high values of lipid content both effects more fairly balance each other.

\subsection{Economic evaluation}

The graph of Fig. 4 shows the influence of the microalgae cultivation area on the NPV and IRR values. For this it was assumed fixed values of lipid content $(30 \%)$, areal productivity $\left(30 \mathrm{~g} / \mathrm{m}^{2} / \mathrm{d}\right)$ and selling prices of microalgae oil and biomass ( $2 \in / \mathrm{L}$ and $1 \in / \mathrm{kg}$, respectively). In this analysis it was considered a number of process units sufficient to process in $8 \mathrm{~h}$ daily all the biomass that grows in a $24 \mathrm{~h}$ period. Thus, for cultivation areas up to $10,000 \mathrm{~m}^{2}$ one equipment piece per process step is enough, but for larger areas more equipment pieces have been considered depending on their capacity and quantity of biomass to be processed.

Results show that IRR and NPV are more influenced by the process operation if small cultivation areas (below $30,000 \mathrm{~m}^{2}$ ) are used. For larger cultivation areas, in particular larger than $60,000 \mathrm{~m}^{2}$, the cultivation area has a negligible effect on the IRR that tends to a limit value of around $26 \%$, although the NPV continues to increase. Therefore, one concludes that increasing the cultivation area and thus, adding more pieces of equipment needed to process more biomass, will only result in small gains in terms of economic performance, visible on the IRR behavior tending to a limit value. However, for small cultivation areas, due to variations observed in the IRR value, one needs to ensure that the correct number of equipment pieces are used, and that its total capacity is adjusted to the needs, in order to simplify the process layout, implementation, operation and maintenance. In order to evaluate the influence of the microalgae lipid content on the process economic performance it was analyzed how it varies the IRR as a function of the cultivation area for three different microalgae lipid contents (10, 30 and $50 \mathrm{wt} \%)$. It was concluded that the process profitability vary, depending on the lipid content, but not its overall qualitative behavior maintaining the shape of the graph curve (as shown in Fig. 4a for IRR). This means that for large cultivation areas (above $50,000 \mathrm{~m}^{2}$ ) the process profitability flattens, or tends to a limit value. Therefore, higher cultivation areas do not correspond to higher profitability values, as increased investment and operational costs, mainly due to more equipment pieces and energy consumption respectively, counter- balances the increasing revenue from oil and/or biomass produced. Thus, for larger cultivation areas sustainability 
issues related to land occupation may be more important that economic issues, as profitability, will not vary significantly.

Concerning the process layout, two different scenarios were evaluated for the process profitability in function of the microalgae lipid content: (1) the case where only one piece of equipment per process step is used, which is possible only for smaller cultivation areas (up to about $10,000 \mathrm{~m}^{2}$ ) and, (2) the case where very large cultivation areas (above $50,000 \mathrm{~m}^{2}$ ) are used, when IRR approaches an asymptotic value, and the number of equipment pieces is adjusted to the biomass processing needs. Results show that the difference between IRR of both scenarios is small (about $6 \%$ ), and in many cases the utilization of more than one piece of equipment per process step may be not justifiable. Also, a linear dependence between IRR and the microalgae lipid content is observed. For the parameter set considered in this study the IRR values are always larger than the debt cost of $10 \%$, showing that it is profitable for the conditions assumed. For other conditions, it should also be possible to estimate the same way, the minimum microalgae cultivation area needed to reach break-even. A more in depth analysis is presented below.

From a process design and operational point of view the areal productivity is more relevant than the microalgae lipid content, as the total biomass that can be obtained in the plant directly depends on it. In particular, the areal productivity is the main factor controlling the cultivation area needed to ensure that the process equipment is used at its full capacity or the closest possible to it. Thus, in order to evaluate how the cultivation area and the process profitability vary depending on the microalgae lipid content, the graph curves of Fig. 5 were represented. For this calculation it was assumed that only one piece of equipment is used per process step (since for greater areal productivities less area is needed for cultivation), microalgae lipid content is $30 \mathrm{wt} \%$, and selling prices of microalgae oil and dry biomass are respectively, $2 € / \mathrm{L}$ and $1 € / \mathrm{kg}$. Results show that as expected, the cultivation area lowers and the process profitability (measured by IRR) increases, as the areal productivity increases.

From a company point of view, it is desirable to calculate the selling prices of microalgae oil and extracted biomass that at the least cover the costs of cultivating and processing microalgae. For this analysis, two scenarios were considered: (1) the case in which the only revenue comes from selling microalgae oil, and (2) the case in which the selling price of extracted biomass is half that of microalgae oil. Both scenarios are presented in Fig. 6 as a function of the microalgae lipid content, for three different areal productivities (20, 30 and $40 \mathrm{~g} / \mathrm{m}^{2} / \mathrm{L}$ ), and a cultivation area of $5000 \mathrm{~m}^{2}$. Results show that, as stated before, the possibility of selling the extracted biomass improves the process economics significantly, in particular, when the microalgae lipid content and/or the areal productivity are low. Also, Fig. 6 shows that the effect of the areal productivity increase is 
smaller than the possibility of selling the extracted biomass together with the microalgae oil. This graph also shows the microalgae oil prices above which the process profitability is positive. For example, a microalgae oil price above 3.04 $€ / \mathrm{L}$, with extracted biomass price of $1.52 € / \mathrm{kg}$ (considering $20 \mathrm{~g} / \mathrm{m}^{2} / \mathrm{L}$ of areal productivity and $30 \mathrm{wt} \%$ of lipid content) or, if the extracted biomass is not sold, for the same conditions the oil price must be greater than $6.45 \in / L$. The graph also shows that if the extracted biomass is sold together with the microalgae oil, the influence of the microalgae lipid content on the process profitability is smaller.

\section{Conclusion}

The sustainability of microalgae biodiesel is heavily dependent on lipid content, which the higher the more sustainable is. Harvesting and lipids separation are the life cycle steps where improvements will have the most significant impact from a sustainability and even economic point of view, as lower energy consumption will reduce operational costs. Concerning economics, currently microalgae oil is not competitive with other biofuels and fossil diesel. The main factors influencing the overall process profitability are the lipid content, areal productivity, and prices of microalgae oil and of extracted biomass.

\section{References}

Benemann, J.R., Oswald, W.J., 1996. Systems and economic analysis of microalgae ponds for conversion of $\mathrm{CO} 2$ to biomass. Final Report to the Pittsburgh Energy Technology Center, DOE/PE/93204-T5. Department of, Energy, March 21.

Caetano, N.S., Silva, V.F.M., Mata, T.M., 2012. Valorization of coffee grounds for biodiesel production. Chem. Eng. Trans. 26, 26-272. http://dx.doi.org/10.3303/ CET1226045.

Campbell, P.K., Beer, T., Batten, D., 2011. Life cycle assessment of biodiesel production from microalgae in ponds. Bioresour. Technol. 102, 50-56.

Delrue, F., Setier, P.-A., Sahut, C., Cournac, L., Roubaud, A., Peltier, G., Froment, A.-K., 2012. An economic, sustainability, and energetic model of biodiesel production from microalgae. Bioresour. Technol. 111, 191-200.

Hodaifa, G., Martínez, M.E., Sánchez, S., 2010. Influence of temperature on growth of Scenedesmus obliquus in diluted olive mill wastewater as culture medium. Eng. Life Sci. 10, 257-264.

Khoo, H.H., Sharratt, P.N., Das, P., Balasubramanian, R.K., Naraharisetti, P.K., 
Shaik, S., 2011. Life cycle energy and CO2 analysis of microalgae-to-biodiesel: preliminary results and comparisons. Bioresour. Technol. 102, 5800-5807.

KPMG, 2013. <http://www.kpmg.com/global/en/whatwedo/tax/taxtools-and resources/pages/corporate-tax-rates-table.aspx $>$ (accessed 9.12.13)

Lardon, L., Hélias, A., Sialve, B., Steyer, J.P., Bernard, O., 2009. Life cycle assessment of biodiesel production of microalgae. Environ. Sci. Technol. 43, 6475-6481.

Maeda, K., Owada, M., Kimura, N., Omata, K., Karubd, I., 1995. CO2 fixation from the flue gas on coal-fired thermal power plant by microalgae. Energy Convers. Manag. 36 (6-9), 717-720.

Mandal, S., Mallick, N., 2011. Waste utilization and biodiesel production by the green microalga Scenedesmus obliquus. Appl. Environ. Microbiol. 77, 374-377.

Mata, T.M., Cardoso, N., Ornelas, M., Neves, S., Caetano, N.S., 2010a. Sustainable production of biodiesel from tallow, lard and poultry fat and its quality evaluation. Chem. Eng. Trans. 19, 13-18.

Mata, T.M., Martins, A.A., Caetano, N.S., 2010b. Microalgae for biodiesel production and other applications. Renew. Sust. Energy Rev. 14, 217-232.

Mata, T.M., Martins, A.A., Sikdar, S., Costa, C.A.V., 2011. Sustainability considerations of biodiesel based on supply chain analysis. Clean Technol. Environ. Policy 13, 655-671.

Mata, T.M., Martins, A.A., Sikdar, S., Costa, C.A.V., Caetano, N.S., 2013a. Sustainability analysis of biofuel processes through the supply chain using indicators. Sust. Energy Technol. Assess. 3, 53-60.

Mata, T.M., Melo, A.C., Meireles, S., Mendes, A.M., Martins, A.A., Caetano, N.S., 2013b. Potential of microalgae Scenedesmus obliquus grown in brewery wastewater for biodiesel production. Chem. Eng. Trans. 32, 901-906. http://dx.doi.org/10.3303/ CET1332151.

Mata, T.M., Melo, A.C., Simões, M., Caetano, N.S., 2012. Parametric study of a brewery effluent treatment by microalgae Scenedesmus obliquus. Bioresour. Technol. 107, 151-158.

Molina Grima, E., Belarbi, E.-H., Acién Fernández, F.G., Robles Medina, A., Chisti, Y., 2003. Recovery of microalgal biomass and metabolites: process options and economics. Biotechnol. Adv. 20, 491-515.

Morais, S., Mata, T.M., Ferreira, E., 2010. Life cycle assessment of soybean biodiesel and LPG as automotive fuels in Portugal. Chem. Eng. Trans. 19, 267272 .

Pfromm, P.H., Amanor-Boadu, V., Nelson, R., 2011. Sustainability of algae derived biodiesel: a mass balance approach. Bioresour. Technol. 102, 11851193.

Ruiz-Marin, A., Mendoza-Espinosa, L.G., Stephenson, T., 2010. Growth 
and nutrient removal in free and immobilized green algae in batch and semicontinuous cultures treating real wastewater. Bioresour. Technol. 101, 5864 .

Shurin, J.B., Abbott, R.L., Deal, M.S., Kwan, G.T., Litchman, E., Mcbride, R.C., Mandal, S., Smith, V.H., 2013. Industrial-strength ecology: trade-offs and opportunities in algal biofuel production. Ecol. Lett. 16, 1393-1404.

Smith, J., Charter, E., 2010. Functional Food Product Development. Blackwell Publishing Ltd., Oxford, UK.

SunEarthTools, 2013. <http://www.sunearthtools.com/dp/tools/CO2emissions calculator.php?lang $=p t \# t x t C O 2 \_9>($ accessed 6.12.13) 


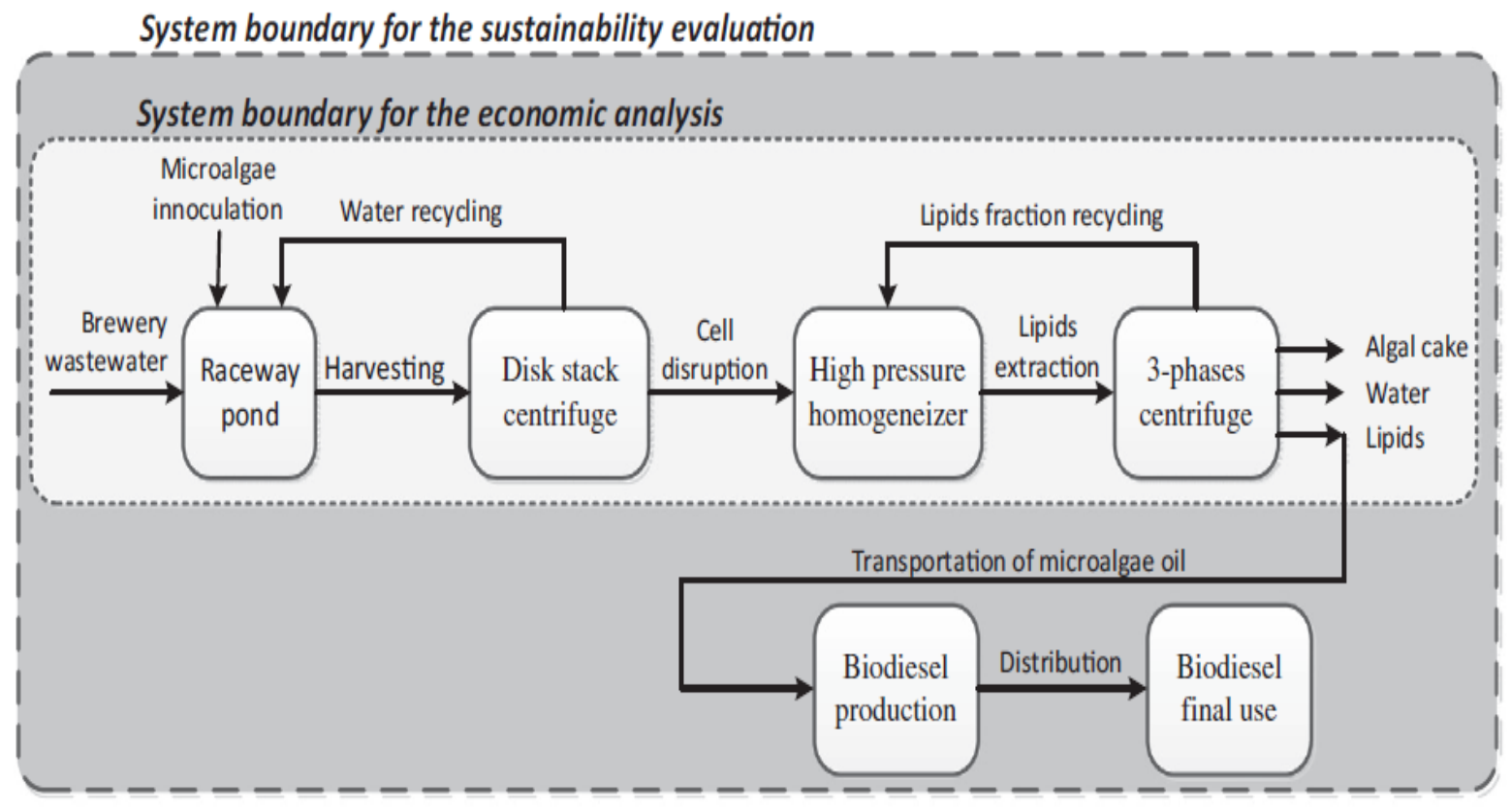

Fig. 1. Schematic representation of microalgae processing for biodiesel production, showing the system boundaries defined for the economic and sustainability evaluation. 


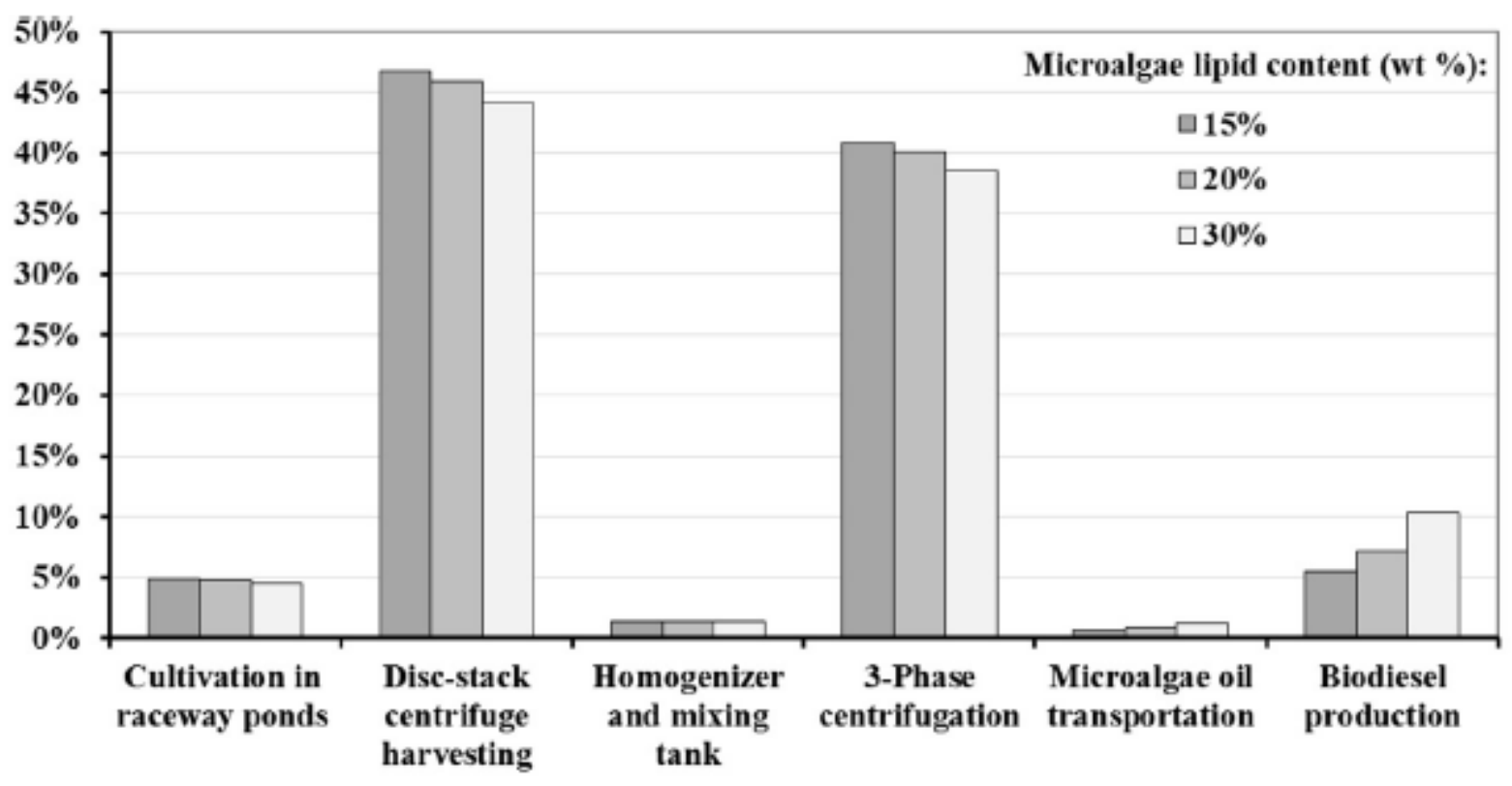

(a)

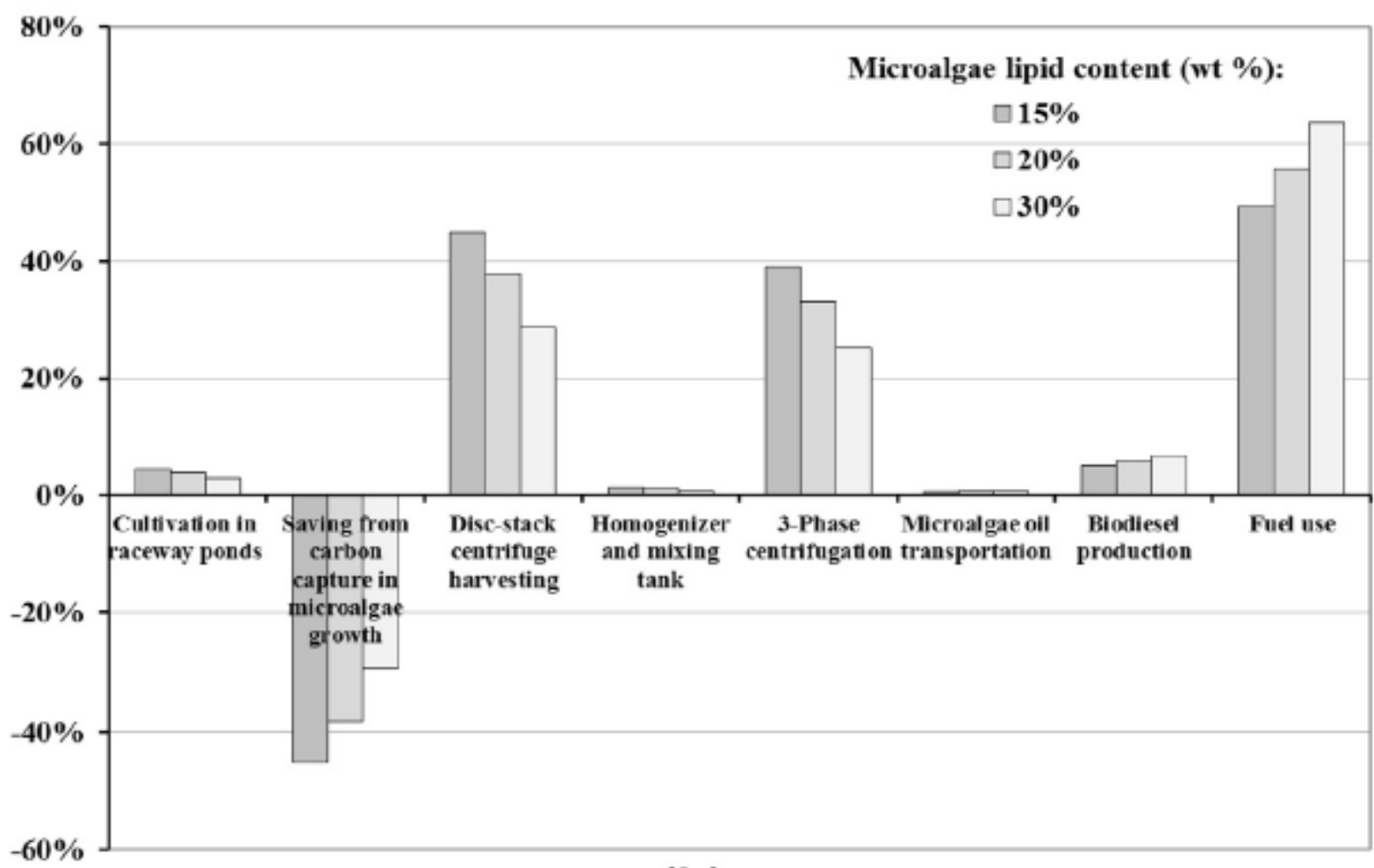

(b)

Fig. 2. Relative percentage of each life cycle step contributing to (a) energy consumption and to (b) net greenhouse gas emissions of biodiesel production, considering microalgae lipid contents of 15, 20 and $30 \mathrm{wt} \%$. 


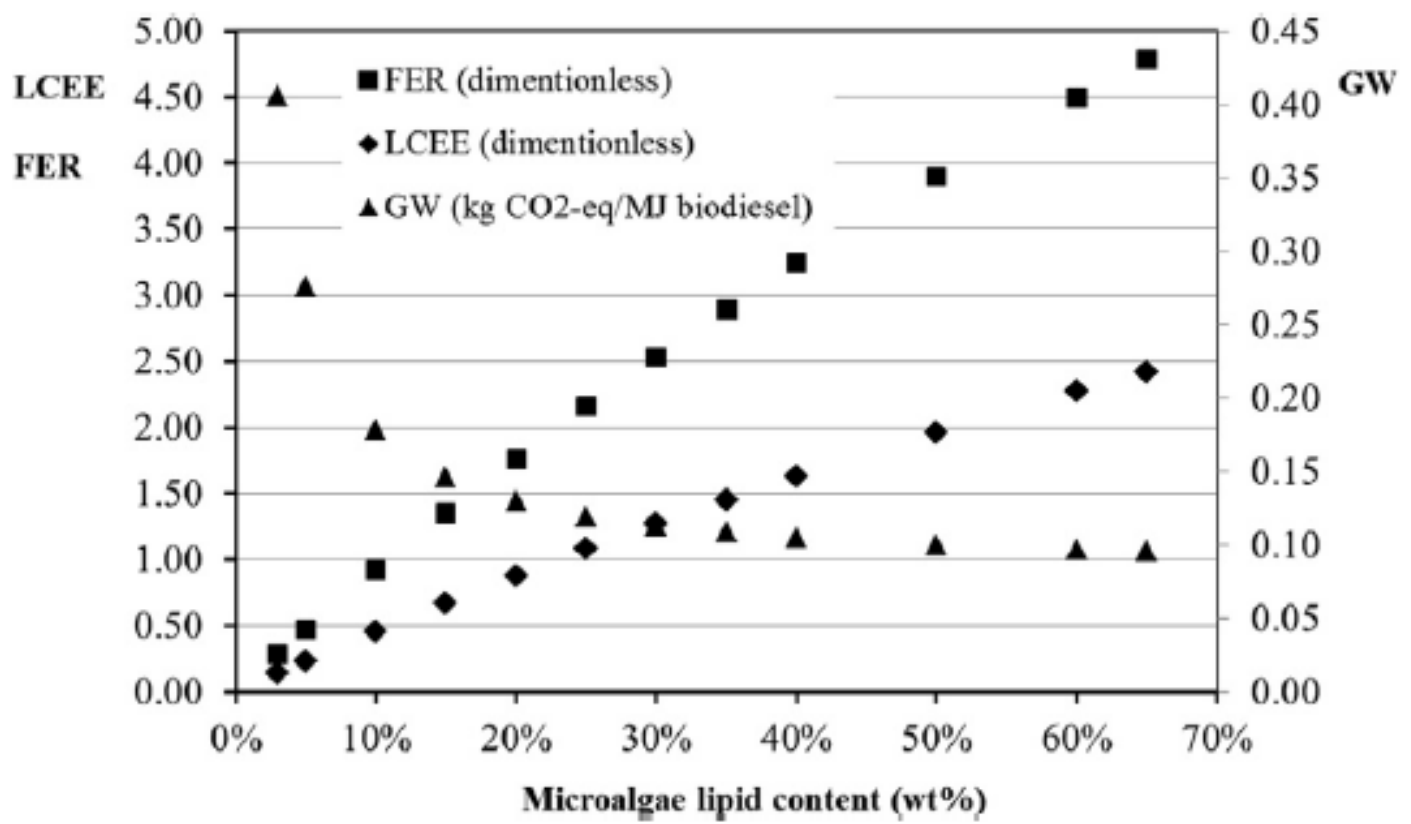

Fig. 3. Sustainability indicators of microalgae biodiesel: LCEE, FER and GW, considering a lipid content from 3 to $65 \mathrm{wt} \%$.

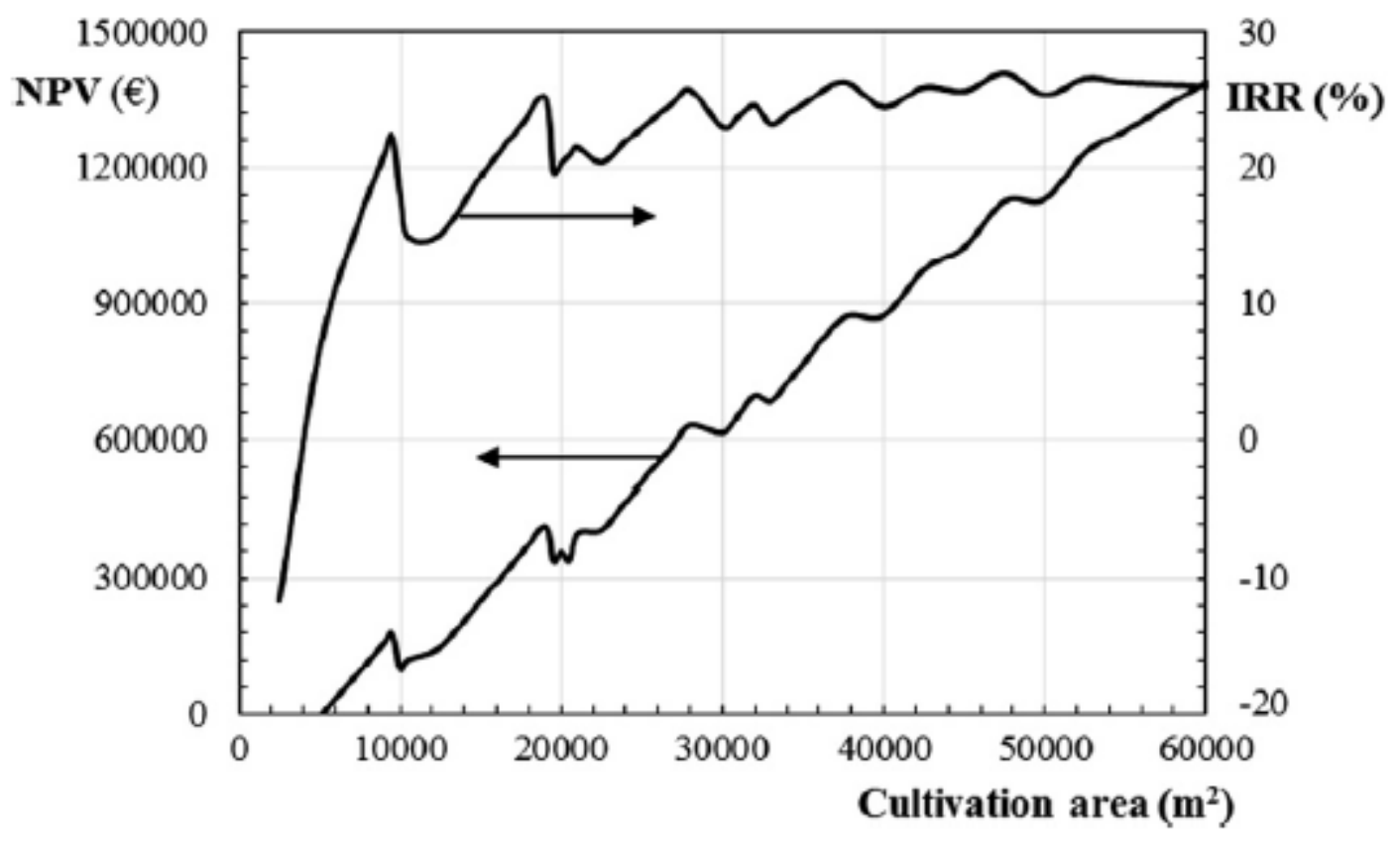

Fig. 4. NPV and IRR as a function of the open ponds' cultivation area. 


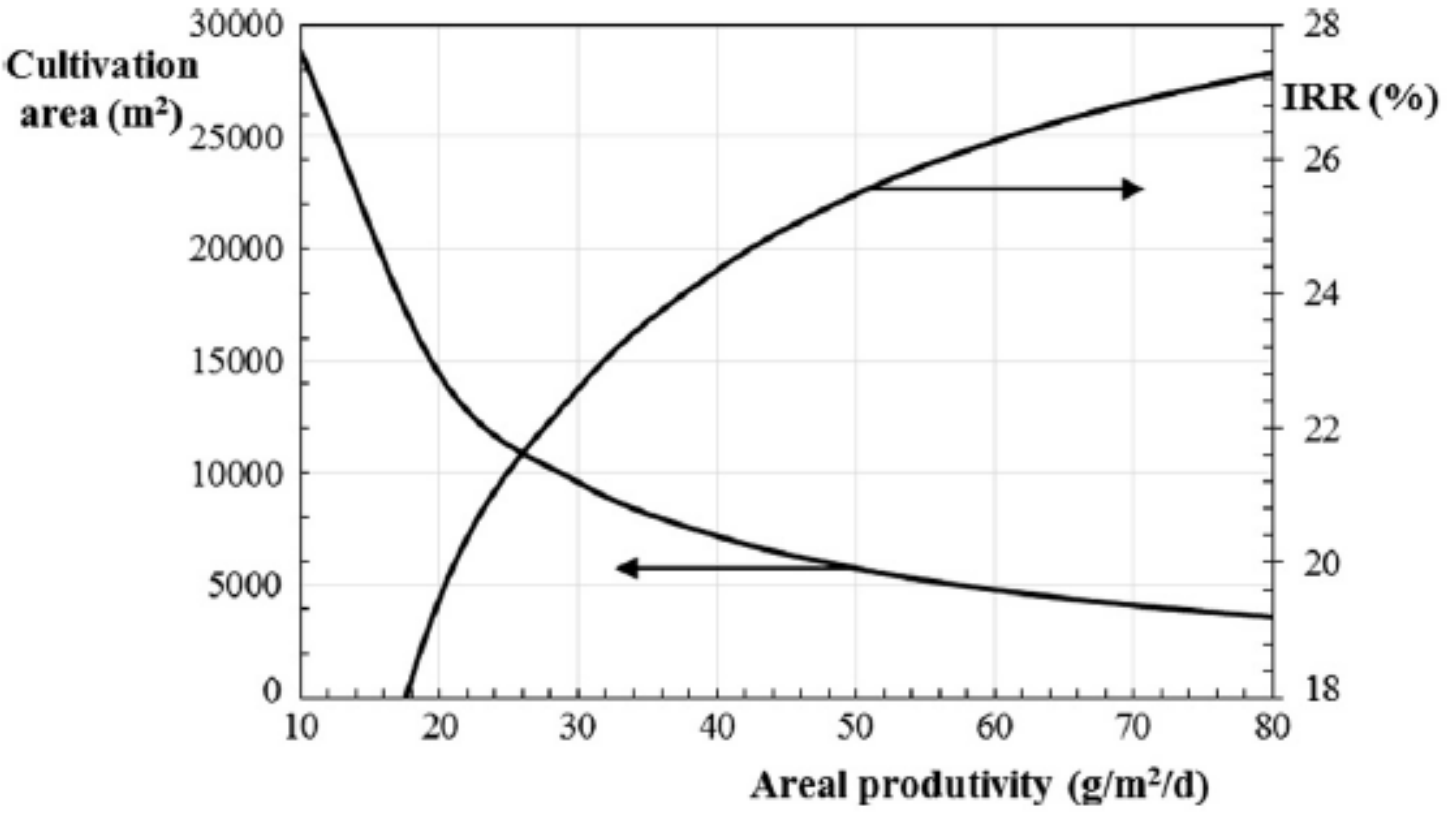

Fig. 5. Cultivation area and IRR as a function of the microalgae's areal productivity, assuming that only one process unit is used per life cycle step

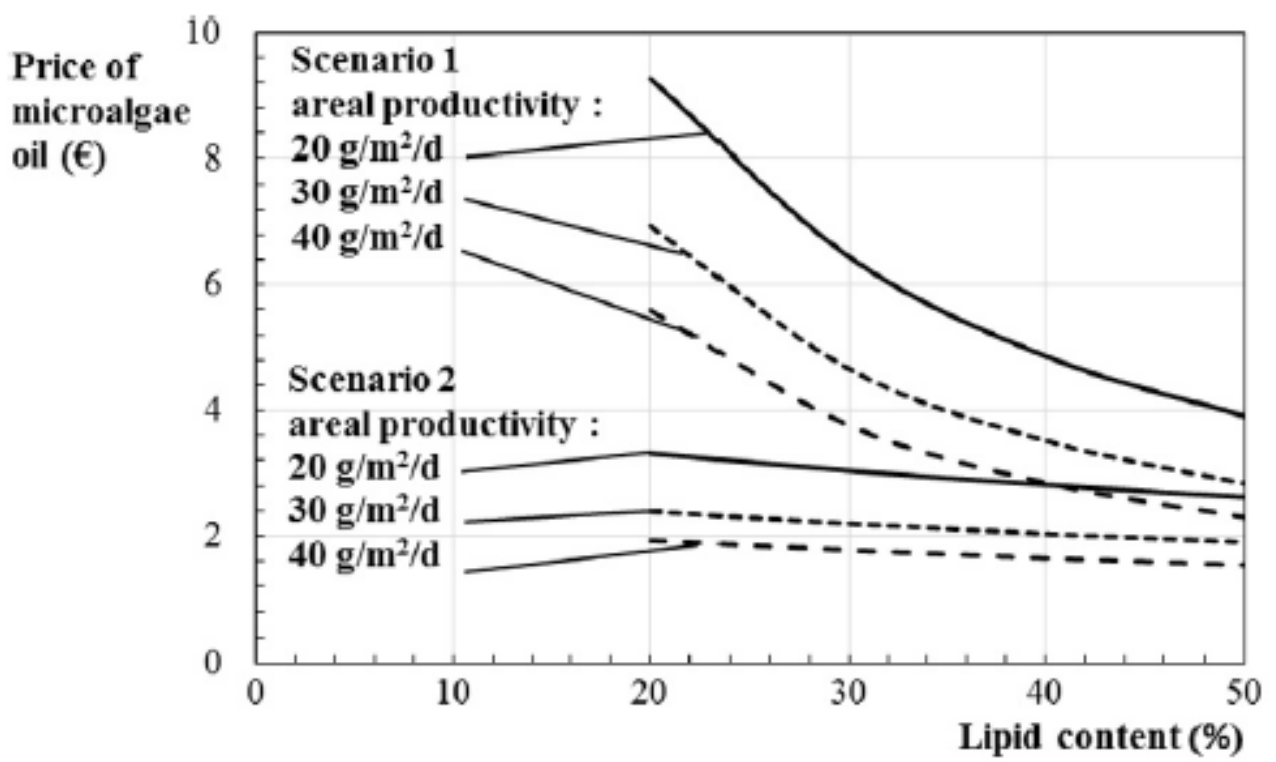

Fig. 6. Selling price of microalgae oil for ensuring the process economic viability, considering two scenarios: (1) in which the only revenue comes from selling microalgae oil, and (2) in which the selling price of extracted biomass is half that of microalgae oil. 
Table 1

Sustainability indicators for the microalgae biodiesel in this study, considering the lipid content of 15,20 and $30 \mathrm{wt} \%$, and the values obtained in another study (Mata et al., 2011) for various biodiesels and fossil diesel.

\begin{tabular}{|c|c|c|c|c|c|c|c|c|c|}
\hline \multirow{2}{*}{$\begin{array}{l}\text { Indicators/feedstock's lipid } \\
\text { Content (wt\%) }\end{array}$} & \multicolumn{3}{|c|}{ Microalgae biodiesel $^{\mathrm{a}}$} & \multirow{2}{*}{$\begin{array}{l}\text { Palm biod. }^{\text {b }} \\
36 \%\end{array}$} & \multirow{2}{*}{$\begin{array}{l}\text { Sunflower biod. }{ }^{\text {b }} \\
40 \%\end{array}$} & \multirow{2}{*}{$\begin{array}{l}\text { Rapeseed biod. } \\
41 \%\end{array}$} & \multirow{2}{*}{$\begin{array}{l}{\text { Soybean } \text { biod. }^{\mathrm{b}}}^{18 \%}\end{array}$} & \multirow{2}{*}{$\begin{array}{l}\text { Microalgae biod. }^{\text {b }} \\
30 \%\end{array}$} & \multirow{2}{*}{$\begin{array}{l}\text { Fossil diesel }^{\mathrm{b}} \\
\text { - }\end{array}$} \\
\hline & $15 \%$ & $20 \%$ & $30 \%$ & & & & & & \\
\hline LCEE & 0.67 & 0.88 & 1.27 & 1.04 & 1.28 & 1.89 & 0.41 & 1.84 & 6.25 \\
\hline FER & 1.35 & 1.76 & 2.53 & 1.04 & 1.28 & 1.40 & 0.41 & 0.56 & 6.25 \\
\hline GW & 0.15 & 0.13 & 0.11 & 0.04 & 0.05 & 0.08 & 0.13 & 0.14 & 0.10 \\
\hline
\end{tabular}

${ }^{\text {a }}$ This study.

${ }^{\mathrm{b}}$ Mata et al. (2011). 